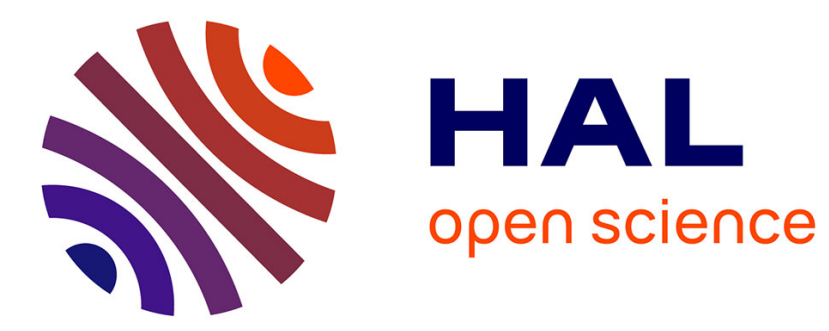

\title{
Power Electric Aiding Controller for Automated Bus Stopping
}

Jorge Godoy, Vicente Milanés, Joshué Pérez Rastelli, Jorge Villagra, Carlos González

\section{- To cite this version:}

Jorge Godoy, Vicente Milanés, Joshué Pérez Rastelli, Jorge Villagra, Carlos González. Power Electric Aiding Controller for Automated Bus Stopping. 7th International Conference-Workshop Compatibility and Power Electronics, Jun 2011, Tallinn, Estonia. hal-00737669

\section{HAL Id: hal-00737669 \\ https://hal.inria.fr/hal-00737669}

Submitted on 2 Oct 2012

HAL is a multi-disciplinary open access archive for the deposit and dissemination of scientific research documents, whether they are published or not. The documents may come from teaching and research institutions in France or abroad, or from public or private research centers.
L'archive ouverte pluridisciplinaire HAL, est destinée au dépôt et à la diffusion de documents scientifiques de niveau recherche, publiés ou non, émanant des établissements d'enseignement et de recherche français ou étrangers, des laboratoires publics ou privés. 


\title{
Power Electric Aiding Controller for Automated Bus Stopping
}

\author{
Jorge Godoy, Vicente Milanés, Joshue Pérez, Jorge Villagrá and Carlos González \\ AUTOPIA program, Centre for Automation and Robotics, UPM-CSIC \\ \{jorge.godoy, vicente.milanes, joshue.perez, jorge.villagra, carlos.gonzalez\}@car.upm-csic.es
}

\begin{abstract}
Day by day the number of vehicles on roads is growing, increasing also the number of accidents, traffic jams and carbon dioxide emissions. For this reason, the European Union has adopted an action plan for improving urban mobility where the public transport is the main key. To present day, solutions as special bus lanes, electrical and hydrogen buses and rail-guided buses have been tested and implemented in several cities as London and Madrid. In this article an automated stopping system for electrical buses is presented. Stopping system have been implemented by the AUTOPIA program on an electric minibus and tested on a private circuit with satisfactory results.
\end{abstract}

\section{INTRODUCTION}

During last decade, the number of vehicles on roads is continuously growing over the entire world. Only between years 2000 and 2006, the motorisation rate on the European Union (EU27) has increased from 422 to 466 passengers cars per 1000 habitants; moreover, in the same time interval the EU27 population has growth $2.12 \%$, which finally represents an increase of $12.77 \%$ - around 26 millions - in the number of passenger cars in the EU [1].

This motorisation growth also represents an increase of traffic jams and carbon dioxide emissions. According to the EU green paper for urban mobility [2], the EU economy lost around 100 billion Euros for delays on traffic jams. In a parallel line, and regarding the $\mathrm{CO} 2$ emissions, the urban traffic is responsible for $40 \%$ of them. Additionally, according to the European study "Attitudes on issues related to EU Transport Policy" [3] published on 2007, only $21 \%$ of the EU27 citizens use public transport as main mode of transportation while other $51 \%$ use passenger cars, being the schedule regularity the main reason for this election. Based on these factors, the EU has decided on 2009 to adopt an action plan for urban mobility where the use of public transport is considered as the main key to improve the urban mobility [4].

From the roads point of view, the Public Transport (PT), specifically buses, are more efficient than passenger cars due to the number of persons being transported per occupied area and fuel consumption. Moreover, the use of greener vehicles for PT would further improve this efficiency, reducing the carbon dioxide emissions. Between 2001 and 2006, the Clean Urban Transport for Europe project (CUTE) enclosed on the 5th Framework Program, tested electric bus fleets on 10 European cities with great results [5]. On the 6th
Framework Program, a one-year extension for CUTE project was included as the HyFLEET:CUTE project. Results for both projects showed the great functionality of these vehicles. As a matter of fact, London will include 10 hydrogen buses to their permanent fleet [6].

Furthermore efficiency, safety and accessibility are the pillars for PT in urban environments. According to [7], 21\% of the EU citizens aged more than 55 years use PT as main mode of transportation; if other transit users like the vision impaired, children or people in wheelchairs are considered, the importance of this factor results more obvious. The major advance in improving bus accessibility is the implementation of Low-floor buses, pioneered by the German manufacturer NEOPLAN. The low-floor buses permit passengers to board and alight without stepping up or down from the sidewalk at the bus stop [8]; however, as a study conducted in Caen, France in 90's [9], even a small gap could be a hazard for the above mentioned users.

Up to now, several solutions have been proposed in response to this problem. On [10], the GIBUS and VISÉE systems' field test results are presented. The GIBUS Guidance des autobus en station - project, supported by the French National Institute for Transportation and Safety Research (INRETS), installed a display on the bus board showing the lateral distance from the bus to the docking point to the driver. On the other hand, the VISEE is a vision-based control system designed to guide the bus to the docking point by controlling only the steering wheel, while driver controls the longitudinal displacement - throttle and brake. More recently, the PATH project, from California University at Berkeley, developed a docking system based on magnetic marks installed on the roadways. By detecting the magnetic marks, the on board control system define the vehicle trajectory and controls the bus steering wheel, throttle and pneumatic brakes. PATH system was tested at Washington DC - United States - on 2003; results showed that the system was able to stop at the docking point with a longitudinal error lower than $50 \mathrm{~cm}$ [11]. As main drawback, this system needs to modify the infrastructure - in this case the road - so as to install the magnetic marks for vehicle's positioning.

In this paper, a longitudinal fuzzy-control differential global positioning system (DGPS)-based system for bus docking is presented. The main idea of this design is to 
develop an aiding system capable of stopping the electric minibus with high precision at the bus stop, making easier the access for children, disabled and old people. The system was tested using an AUTOPIA program's electric minibus at the Centre for Automation and Robotics (CAR, UPM-CSIC). CAR's private driving circuit was used in the experimental phase to validate the proposed system. A screen indicates driver when the system can be activated. When it is activated, the minibus longitudinal displacement is controlled by a main computer connected to the electric motor speed controller and an electro-hydraulic braking system specially designed for the application. In order to test the system in traffic situations as close as possible to the real traffic, the steering wheel is controlled by a human driver whether the system is activated or not.

The remainder of this paper is structured as follows: on section I a minibus description is presented, including the design for throttle and brake pedals automation. Section II introduces the trajectory estimation algorithm implemented and describes in detail the main fuzzy-controller designed for stopping the bus with precision. Tests and results data and analysis for both trajectory estimation and stopping performance are presented on section III. Finally, at the paper's end several conclusions and future work are presented.

\section{ElECTRIC BUS DESCRIPTION}

Molinero is the fifth vehicle automated by the AUTOPIA program. It is an electric minibus model EGK6152K (see fig. 1) with capacity for 14 passengers manufactured by Con+Auto [12]. This vehicle counts with four arrays of four $12 \mathrm{~V}$ batteries each and a $5 \mathrm{KW}$ electric motor that allows it to run up to $35 \mathrm{Km} / \mathrm{h}$ with $100 \mathrm{Km}$ autonomy. Molinero was chosen by the AUTOPIA program as a green option for automated public transport in urban environments.

As in previous vehicles, the main sensor on the Molinero's control architecture is a DGPS installed at vehicle rearcentre, which allows the vehicle to sense its position and velocity at $100 \mathrm{~ms}$ rate. The GPS correction is obtained through the WAAS/EGNOS network. It is well-know that, as velocity sensor, the GPS does not represent and optimal option; however, since Molinero does not have an electronic

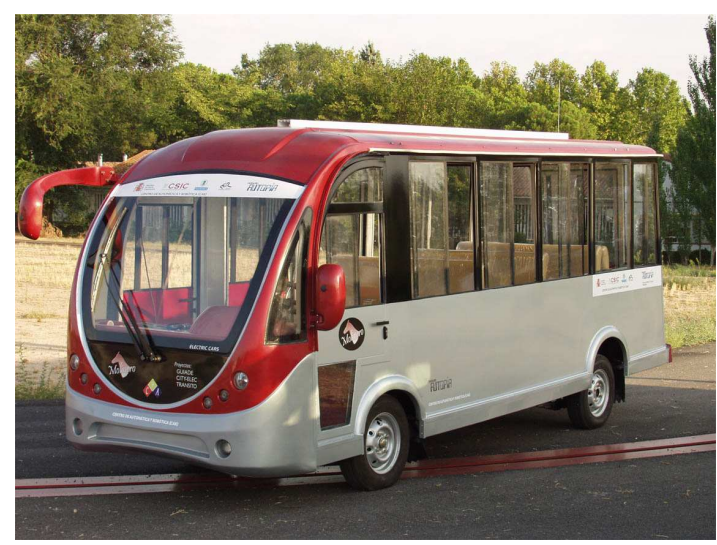

Fig. 1. Electric minibus Molinero calculator on board, the velocity estimation through DGPS is the simplest option with best results. As future work, it is being considered to install an electronic velocity sensor as the one described on [13].

The architecture's backbone is an On-board Control Unit which consists on a solid-state industrial computer for automotive applications. The solid state components allow the computer to work normally under driving conditions, avoiding the common hard disk failures due to vibrations.

\section{LONGITUdinAl CONTROL}

Previously, two electric Citroën Berlingo vans and two gas-propelled Citroën C3 were fully-automated. Although longitudinal control - i.e. throttle and brake pedals automation - has been previously implemented by the AUTOPIA group [14] [15], some modifications had to be applied for a PT vehicle. Specifically, number of passengers, road layout and battery energy were considered so as to design an appropriate longitudinal controller. On next subsections the throttle and brake pedals automation is described.

\section{A. Throttle}

On Molinero, the electric motor is controlled by a speed controller model 1204 manufactured by Curtis. Under normal operation, an electronic throttle pedal provides the throttle reference to the motor speed controller as a 0-5-volts signal and also incorporates a micro-switch that indicates the controller to leave the motor on freewheel when no throttle is applied. In order to emulate the pedal behaviour on the automatic mode, a digital-analogue $\mathrm{I} / \mathrm{O}$ card was installed on the main computer to send the throttle reference; additionally an electronic switch controlled by Controller Area Network (CAN) bus connected on parallel to the pedal micro-switch allows the computer to control the freewheel mode. In fig. 2 a schematic outline of throttle is presented.

\section{B. Electro-Hydraulic Brake}

A bus is considered as a heavy-duty vehicle because it could carry so more people than a familiar vehicle, requiring more power on the brakes to stop the vehicle. However, since Molinero is an electric vehicle, the energy consumed by the automatic braking system is a very critical design factor. Additionally, it must be considered that adding elements to a commercial vehicle is usually a difficult task because

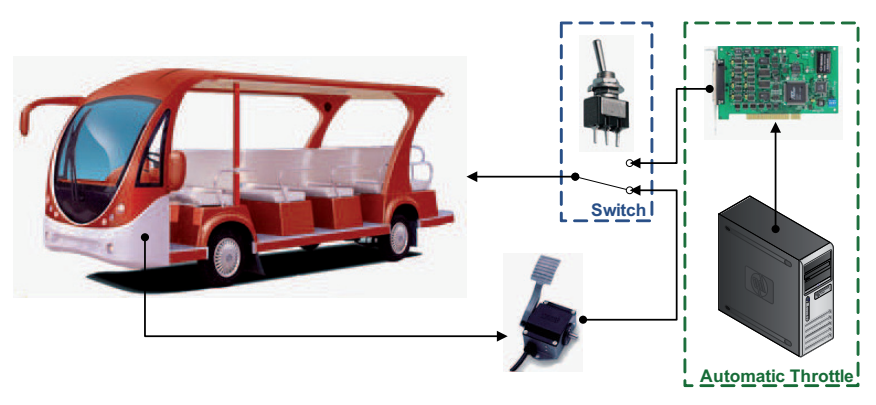

Fig. 2. Throttle outline 
manufactures do not leave much free space for external components. For these reasons, the braking system design should be balanced between power consumption and available space. Based on the AUTOPIA program experience, an electrohydraulic braking system was adapted from a gas-propelled familiar car [16] to our electric minibus.

The hydraulic power system for the autonomous braking is provided by a gear pump coupled to a 12-volt 350watts dc-motor. The pump has a one litre fluid tank which guarantees the needed displacement on the drum brakes. For safety considerations, a limiter tube fixed to 50 bars is added to protect the car elements from excessive pressure. As for throttle, in automated mode it is necessary to control the braking system from the main computer; for this, an electro-proportional pilot is installed after the safety loop. It is in charge of regulating the pressure to be applied from the electro-hydraulic braking power system. This pilot is controlled by a $0-10 \mathrm{~V}$ signal using the same digital-analogue $\mathrm{I} / \mathrm{O}$ card used for the throttle. As the minimal pressure of the electronic pilot is not zero, a spool directional valve is added at the end of the electro-hydraulic braking system to solve this problem. This valve is activated at the same time that the electronic pilot. It is normally close when the braking system is activated. A power relay is in charge of activating this valve in order to permit brake fluid circulation.

The last stage consists on installing an adequate device to permit choosing either the original braking circuit or the automated hydraulic braking power system. Since throttle pedal only manages voltage signals, a two-way switch performs the commutation between original and automated systems. In the brake case, a device to permit introducing the brake fluid coming from the automated system into the minibus brake circuit was installed. To this end, two shuttle valves were installed to interconnect both systems just before the drum actuators. Each valve permits the flow from either of two inlet ports - electro-hydraulic or original braking system - to a common outlet - drums actuators - by means of a freefloating metal ball that shuttles back-and-forth according to the relative pressure at the two inlets. Since the systems must cooperate, the driver could stop the vehicle even when the automated mode is active, improving the safety in case of system failure. A schematic outline of the electro-hydraulic system design is shown in fig. 3 .

\section{CONTRol Algorithm}

Our goal is to develop a system capable of stopping the electric minibus with high precision with respect to a point in the road. This point is located in the bus stop. The automated system can be used as aiding system for disabled or old people in order to make easy the access for the kind of users to the PT.

Although all PTs are guided by a human driver, an aiding system capable of stopping the bus with enough precision can help the bus driver in his task making more comfortable and safe his work. So, two main requirements have to be set before proceeding with the design of the control system:

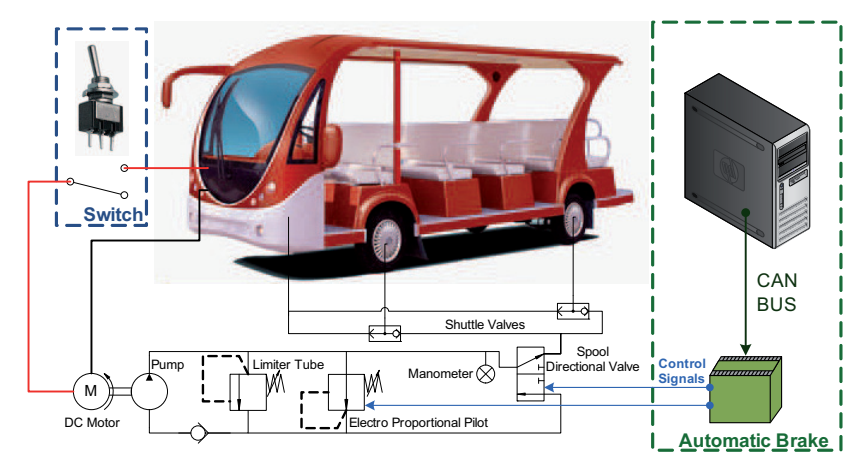

Fig. 3. Electrohydraulic brake outline

- The system has to be capable of detecting the moment to be activated.

- Once the system is activated, it has to be capable of stopping the bus with enough accuracy in the bus stop.

\section{A. Trajectory estimation}

Since the developed application works as an assistance system, one of the main aims is to avoid the need of complex trajectory maps. For this reason, an online simple trajectory estimation algorithm has been implemented to determinate the vehicle route and distance to the stop point. Based on the position data of the last seconds - obtained via the DGPS, the program calculates two regression lines: one for the current trajectory - i.e. the tangent with respect to the current position of the bus - and the other one based on the "accumulate" trajectory - i.e. the tangent with respect to the stretch the bus is covering. The difference between both line slopes permits the program to determinate if the vehicle is either in a curve or in a straight stretch. When the vehicle is in a straight stretch - difference between slopes is lower than 0.02 - the control program calculates the lateral and over-line distance to the stop point and finally, when the lateral distance is lower than 3 metres - vehicle is on a straight trajectory over the bus lane - allows the driver to activate the automated stop system.

\section{B. Fuzzy controller}

The vehicle longitudinal control is performed by a fuzzy controller. The controller is based on a fuzzy coprocessor named ORBEX (Spanish acronym for Fuzzy Experimental Computer) which had been developed previously at the CAR [17]. The ORBEX coprocessor allows to define and implement control rules in a quasi natural language by means of IF... THEN... sentences; for instance:

\section{IF time to arrive big THEN brake null}

where the words in italic are fuzzy variables, the words in bold are ORBEX language keywords, and the words in plain script are linguistic variable values [15]. For this application, two input variables, one output variable and a 9-rules set were defined. 
As inputs to the fuzzy controller, the control program uses two variables: the Time-To-Arrival (TTA) and the NeededAcceleration (NA). The time-to-arrival is defined as the overline distance to stop point divided by the current vehicle velocity 1 , while the Needed-Acceleration is defined as the constant deceleration needed to stop the vehicle at the stop point based on the current velocity 2 . For both input variables, three membership trapezoidal functions were defined, as can be seen in fig. 4 .

$$
\begin{aligned}
& \text { TTA }=\frac{\text { Distance }}{\text { CurrentVelocity }} \\
& N A=\frac{\text { CurrentV } \text { elocity }^{2}}{2 \text { Distance }}
\end{aligned}
$$

The controller output is defined as the normalized pressure applied by the Electro-Hydraulic circuit to brake. As can be seen in fig. 5, five singletons were defined for the output defuzzification. Negative values are a software consideration to indicate to the control program that brake is applied and any throttle input should be dismissed. Despite the throttle is automated, it was not implemented as controller output in order to guarantee an efficient brake, stopping the vehicle uniformly and making unnecessary increasing velocity in any moment. The fuzzy rule set is defined as below:

\section{IF TTA Big AND NA Neg THEN Pedal Brake_Little \\ IF TTA Big AND $N A$ Zero THEN Pedal Nothing \\ IF TTA Big AND $N A$ Pos THEN Pedal Nothing \\ IF TTA Med AND NA Neg THEN Pedal Brake_Medium \\ IF TTA Med AND NA Zero THEN Pedal Brake_Little \\ IF TTA Med AND NA Pos THEN Pedal Nothing \\ IF TTA Small AND NA Neg THEN Pedal Brake_Much \\ IF TTA Small AND NA Zero THEN Pedal Brake \\ IF TTA Small AND NA Pos THEN Pedal Brake_Much}

\section{IMPLEMENTATION}

\section{A. Experimental driving circuit}

All the experimental tests have been performed at the CAR's private driving circuit. In fig. 6 an aerial image of
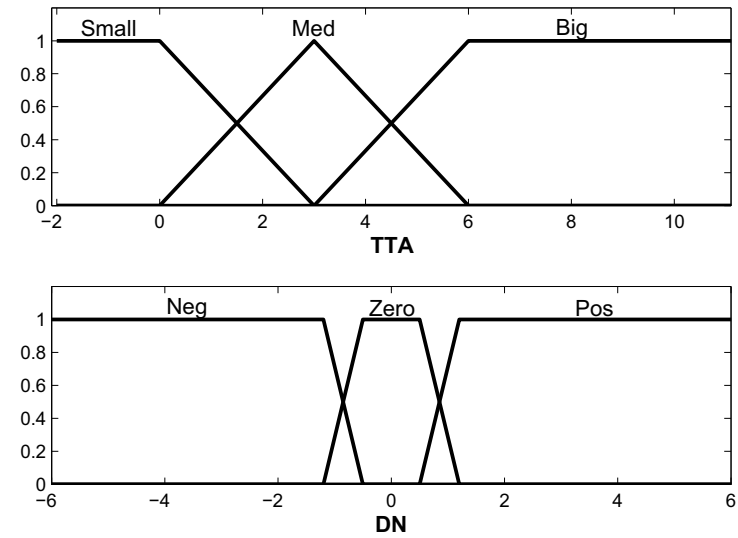

Fig. 4. Fuzzy controller inputs membership functions

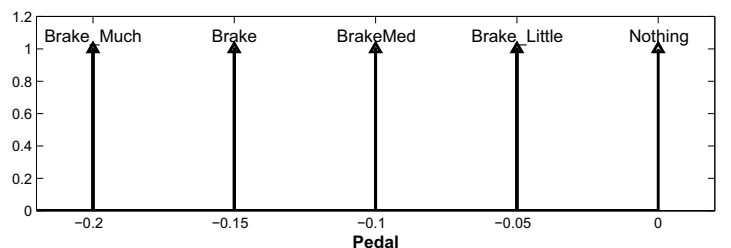

Fig. 5. Fuzzy controller output membership functions

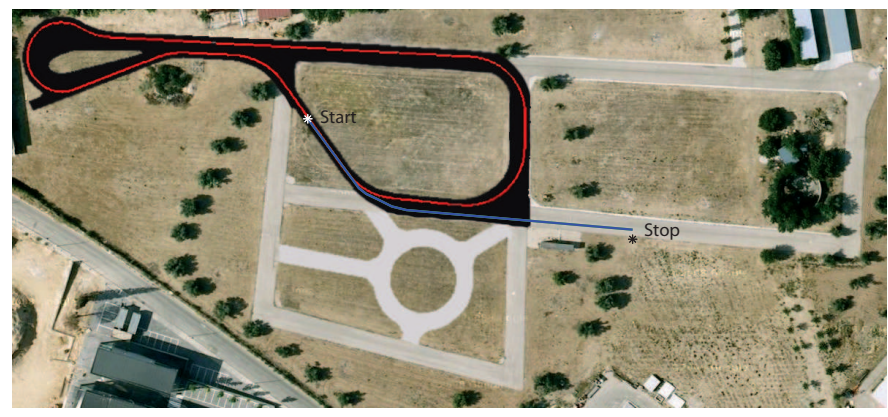

Fig. 6. Experimental test cricuit

the circuit can be appreciated, including the start point, the stop point - located at the bus stop - and the approximate bus trajectory for all tests. Both start and stop points have been selected to demonstrate the trajectory adjustment algorithm and bus stopping performance.

\section{B. Trajectory estimation}

In order to validate the trajectory adjustment algorithm performance, several tests were performed before implementing the stop controller. After the first data analysis, it was found that the regression line adjustment was not precise enough at low speed - lower than 7 kilometres per hour - in some cases, because of high frequency changes due to the proximity of the position points measured. For this reason, the regression algorithm was modified to keep the last iteration line slope at velocities lower than 7 kilometre per hour and only calculate the mass centre of points where the line should cross.

In fig. 7, a test of the trajectory estimation is presented. The first graph represents the value of each calculated slope - current and "accumulate" trajectory - and the bottom graph shows the vehicle speed. Both graphs are presented over the same time axis. In the slope graph, one can see that, from the start point, the vehicle is over a curve trajectory; however, after the 10th second the difference between both values is almost null, indicating that the vehicle is over a straight stretch. Also it is possible to appreciate that when the speed decreases under the minimal value - near second 18.5 - the slope values are constant. So, these test results prove the correct algorithm performance for the trajectory estimation.

\section{Stopping Performance}

After the trajectory estimation algorithm was validated, the next step was calibration and validation of the stopping 

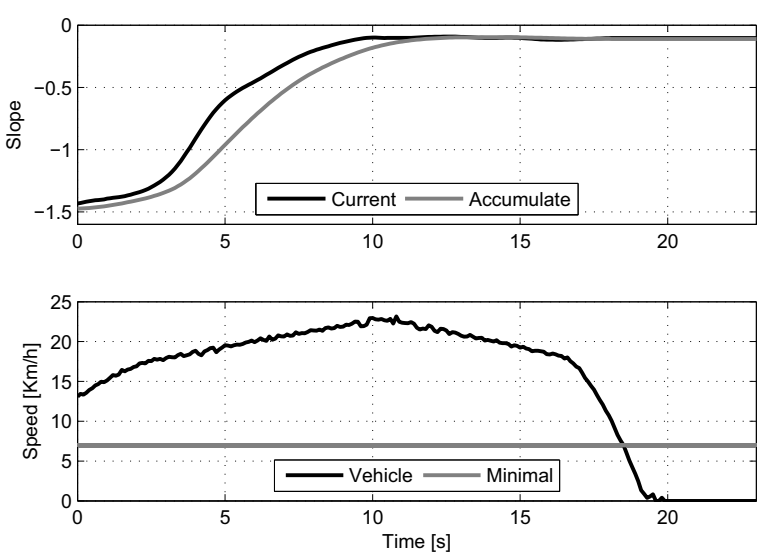

Fig. 7. Trajectory adjustment

controller. As it was mentioned before, the same route presented in fig. 6 was used for the stop test. The stop point position is fixed and it was determinated before tests using the same DGPS installed on vehicle.

In fig. 8 the evolution of the distance to the stop point, vehicle speed, and fuzzy controller inputs and output evolution over time for one case are presented. For this test, the stopping system was activated at around the 8th second, when the vehicle was about 40 metres from the stop point and at a speed of around 20 kilometres per hour. Finally, around the 17th second the vehicle was completely stopped.

From the needed acceleration graph, one can appreciate that the absolute value does not exceed $2 \mathrm{~m} / \mathrm{s}^{2}$, considered as the threshold for maximum acceleration maintaining the passengers comfort [18]. Regarding the controller output, it evolves continuously without reaching the maximum value or saturate. Peaks shown on the graph occur after the vehicle is stopped and they are caused by the front-back movement of the vehicle at the moment it is stopped. However, this effect does not considerably affect the system performance.

When the system is activated, the speed graph shows two deceleration phases around the 14th second, the first one between the 10th and 14th second, when the controller output is under 0.15; and other stage after 14th second when the controller output is bigger than 0.15. Despite this difference, at no given moment the deceleration of the vehicle is bigger than the comfort threshold and the vehicle decelerates uniformly on each stage. For this test the bus stopped at $24 \mathrm{~cm}$ from the stopping point.

Since the number of passengers on board is a factor that could affect the stopping performance due to the vehicle weight changes, several braking tests were made in order to determinate the influence of this factor over the system developed. Data analysis showed that, as supposed, the vehicle deceleration under constant brake pressure decreases when the number of passengers is bigger. Fig. 9 shows the speed evolution for 1 and 9 passengers and fixed values for the controller output. As can be appreciated on graph, with 9 passengers on board, the stop time increases 5, 4
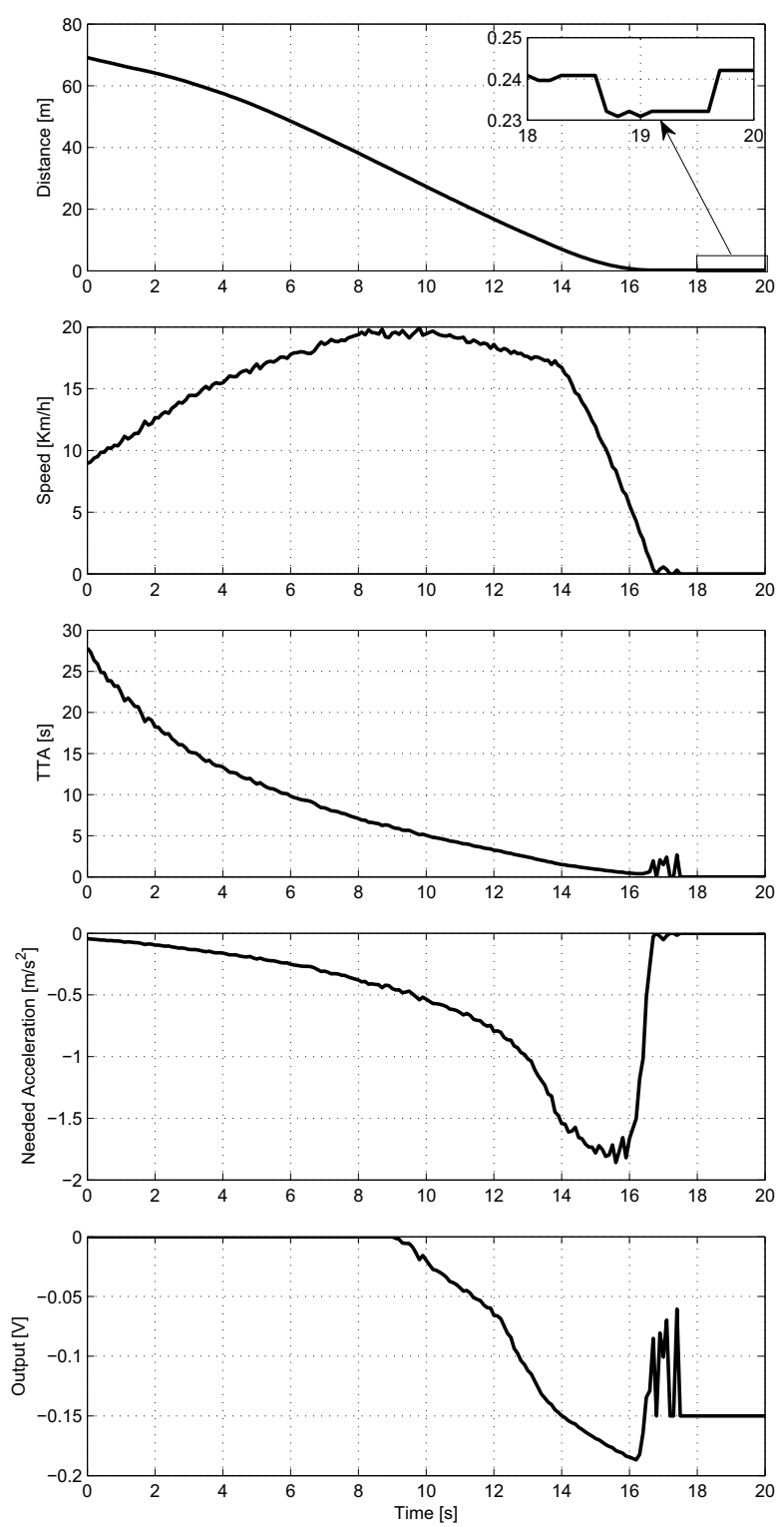

Fig. 8. Stopping controller test

and 0.5 seconds respect to the 1-passenger stop time for a $0,-0.1$ and -0.2 pedal value respectively. Despite this stop time increments, automatic stopping tests performed with different number of passenger showed that the implemented fuzzy controller is able to manage this situation without any modification; meaning that the passenger number increase just causes a faster change on the output value without passenger comfort being affected.

Finally, the system was tested using different people as drivers. A screen was installed in the windshield of the bus so as to advise when the automated stopping system can be used. The system was available to be activated by the drivers while the needed-acceleration value was to be lower than $2 \mathrm{~m} / \mathrm{s}^{2}$. For all tests performed using different drivers and different number of passengers in the bus, the vehicle stopped between 5 and $35 \mathrm{~cm}$ from the stopping point. A 

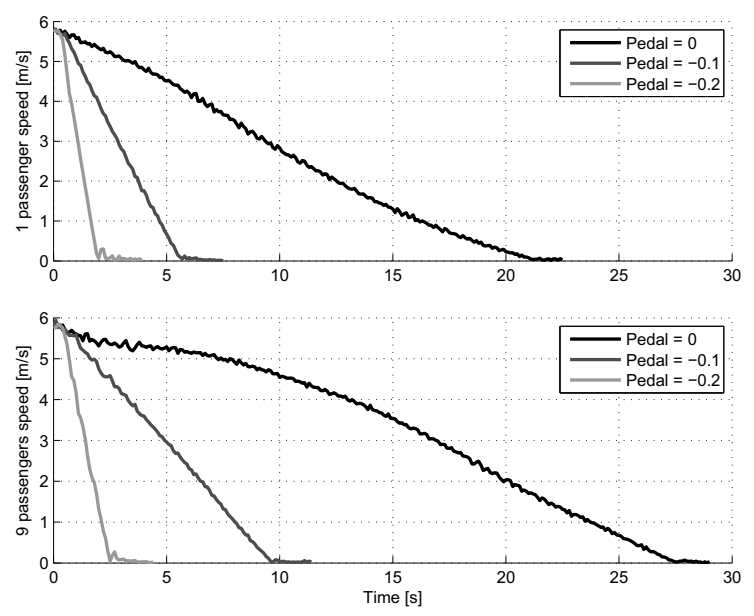

Fig. 9. Brake tests

video file of the stopping system could be retrieved from http://www.iai.csic.es/users/autopia/Videos/BusStopping.wmv

\section{CONCLUSIONS}

The automated bus stopping control for an electric minibus using fuzzy logic has shown promising results. The required information for the control loop comes from a Differential GPS, notwithstanding the modularity of the control scheme proposed allows to add others sensors, which would improve the input data.

Furthermore, the simple trajectory estimation algorithm proposed in this work has shown good performance. Two regression lines allow to determine when the vehicle is in straight and curve segments. Moreover, the stopping system considers fast and smooth responses. The deceleration of the minibus never exceeds $2 \mathrm{~m} / \mathrm{s}^{2}$, providing a comfort sensation for all the passengers.

The control scheme, based on fuzzy logic, allows emulating the human behavior in the driving process. Final tests, considering an empty and a full minibus, show that the fuzzy logic is a good alternative to control system with different dynamics, as well as in the platform used in this work.

Finally, a new green and intelligent public transport system, which controls the brake and throttle in a commercial minibus, has been developed. This is the main contribution of this paper.

Other control strategies, such as neuro-fuzzy and genetic algorithm, will be considered to improve the tuning of the fuzzy controllers proposed in this work. An entire autonomous driving will allow a better use of energy on the minibus, helping to reduce the $\mathrm{CO} 2$ emissions in urban environments.

\section{ACKNOWLEDGMENT}

This work was supported by the Spanish Ministry of Science and Innovation by means of Research Grant TRANSITO TRA2008-06602-C03 and Spanish Ministry of Development by means of Research Grant GUIADE P9/08.
J. Godoy wants to specially thank to the JAE program (Consejo Superior de Investigaciones Científicas) for its support in the development of this work.

\section{REFERENCES}

[1] http://epp.eurostat.ec.europa.eu/.

[2] Green Paper: Towards a new culture for urban mobility - COM(2007) 551. European Commission, 2007.

[3] T. G. Organization, Attitudes on issues related to EU Transport Policy - Analitical Report. Eurobarometer - European Commission, 2007.

[4] Action Plan on Urban Mobility - COM(2009) 490. European Commission, 2009

[5] http://www.global-hydrogen-bus-platform.com/.

[6] http://www.tfl.gov.uk/corporate/6585.aspx.

[7] Informe 2006 OMM. Observatorio Movilidad Metropolitana, 2008.

[8] J. B. Michael, "Safety analysis of concept systems for guidance and control of transit buses final report for mou 327," 1999.

[9] P. Lesauvage, M. Dejeammes, and C. J., "Experience of street-level access to buses in the french city of caen," in Proceedings of the 22nd European Transport Forum: Public Tranport Planning and Operations, 1994.

[10] M. Dejeammes, F. Coffin, T. Ladreyt, M. F. Dessaigne, V. Fouet, C. Dolivet, and R. Zac, "Bus stop design and automated guidance for low-floor buses: Evaluation of prototypes with investigation of human factors," Journal of the Transportation Research Board, vol. 1666, pp. 85-91, 1999.

[11] H.-S. Tan, "Develop precision docking function for bus operation final report for mou 397," 2003.

[12] http://www.conmasauto.com/.

[13] J. Perez, F. Seco, V. Milanes, A. Jiménez, J. Díaz, and T. de Pedro, "Rfid-based intelligent vehicle speed controller using active traffic signals," SENSORS, 2010.

[14] V. Milanés, J. Pérez, E. Onieva, C. González, and T. de Pedro, "Electric power controller for steering wheel management in electric cars," in Proc. CPE '09. Compatibility and Power Electronics, 2009, pp. 444 449.

[15] E. Onieva, V. Milanés, C. González, T. de Pedro, J. Perez, and J. Alonso, "Throttle and brake pedals automation for populated areas," ROBOTICA, vol. 28, no. 4, pp. 509-516, 2010.

[16] V. Milanes, C. Gonzalez, J. Naranjo, E. Onieva, and T. De Pedro, "Electro-hydraulic braking system for autonomous vehicles," International Journal of Automotive Technology, vol. 11, no. 1, pp. 89-95, Feb 2010.

[17] R. García and T. de Pedro, "First application of the orbex coprocessor: Control of unmanned vehicles," EUSFLAT-ESTYLF Joint Conference. Mathware and Soft Computing, vol. 7(2-3), pp. 265-273, 2000.

[18] V. MIlanés, "Sistema de control de tráfico para la coexistencia entre vehículos autónomos y manuales mediante comunicaciones inalámbricas," Ph.D. dissertation, Universidad de Alcalá, 2010. 